\title{
Formulation Design and Development of a Unani Transdermal Patch for Antiemetic Therapy and Its Pharmaceutical Evaluation
}

\author{
Mohd Nauman Saleem ${ }^{1}$ and Mohammad Idris ${ }^{2}$ \\ ${ }^{1}$ Post Graduate Department of Ilm-us-Saidla, Ayurvedic \& Unani Tibbia College, Karol Bagh, New Delhi 110005, India \\ ${ }^{2}$ Departments of Ilm-us-Saidla \& Advia, Ayurvedic \& Unani Tibbia College, Karol Bagh, New Delhi 110005, India
}

Correspondence should be addressed to Mohd Nauman Saleem; nauman.saleem14@gmail.com

Received 28 December 2015; Revised 30 March 2016; Accepted 4 May 2016

Academic Editor: Giuseppe Comi

Copyright (C) 2016 M. N. Saleem and M. Idris. This is an open access article distributed under the Creative Commons Attribution License, which permits unrestricted use, distribution, and reproduction in any medium, provided the original work is properly cited.

\begin{abstract}
The Transdermal Drug Delivery System (TDDS) is one of the novel routes for systemic delivery of drugs through intact skin. A transdermal patch (TP) is a medicated patch that is placed on skin for delivery of medication through skin into the blood stream. The aim of present study was to formulate and evaluate a Unani transdermal patch that could be used for antiemetic therapy. The incorporation of Unani ingredients, namely, Khardal (Brassica nigra), Zanjabeel (Zingiber officinale), Podina (Mentha arvensis), and Sirka (Vinegar) were envisaged. The TP was prepared by solvent evaporation technique and was evaluated for organoleptic characteristics and other physicochemical properties, such as thickness, weight uniformity, folding endurance, moisture content, drug content, and tolerability and acceptability of patch. The in vitro permeation study of the patch was carried out through Franz diffusion cell using egg shell membrane as barrier membrane. Phosphate buffer $\mathrm{pH} 7.4$ was used as dissolution medium and the temperature was maintained at $37 \pm 1^{\circ} \mathrm{C}$. The in vitro permeation study of the prepared TP indicated a time dependent increase in drug release throughout the study. The percentage of cumulative drug release was found to be $77.38 \%$ in 24 hours. The study shows a new approach to work in Unani pharmaceutics.
\end{abstract}

\section{Introduction}

The Transdermal Drug Delivery System (TDDS) is one of the novel routes for systemic delivery of drugs through the intact skin [1]. The ultimate goal of this dosage design is to maximize the flux through skin and at the same time minimize retention and metabolism of drug in the skin. It also ensures that compounds are delivered, preferably at a specific rate, to the systemic circulation $[2,3]$. The TDDS can deliver certain medications to systemic circulation in a more convenient and effective way than conventional dosage form. The potential of skin as a path of drug administration has been amply demonstrated by the acceptability of marketed therapeutic systems. It is estimated that worldwide market revenues for transdermal products were around US\$ 6 billion in 2009, shared between the USA (56\%), Europe (32\%), and Japan (7\%), and are likely to reach a staggering US\$ 10 billion in 2015 and even more in 2020 [4].
The TDDS offers several significant advantages such as avoidance of the hepatic-first-pass metabolism, avoidance of gastrointestinal drug absorption difficulty, and noninvasiveness. Pharmaceutically, a transdermal patch is a dosage form that is used for delivery of medication through the skin into the blood stream. Following skin permeation, the drug first reaches the systemic circulation and then is transported to the target site, which could be relatively remote from the site of administration, to produce therapeutic action [5].

Though the concept of TDDS happens to be a new one and belongs to conventional pharmacology, Unani classical literature has ample evidence of it. There are a number of single and compound Unani formulations exhibiting transdermal activity mentioned in the celebrated writings of the Unani physicians. One of the oldest evidence of delivering drugs through skin is reported in the 16th Century BC where the husk of castor oil plant in water was placed on an aching head [6]. Also the use of Khardal (Brassica nigra) has been 
in practice right from prehistoric period in the form of mustard plaster which was first described by Dioscorides (circa 1st century CE) more than two thousand years ago [7]. The mustard plasters have also been used to overcome the condition of vomiting $[8,9]$.

Vomiting/emesis (qai) is an abnormal indication of gastrointestinal tract. This situation warrants an urgent medical attention. The oral route of medication is usually not suited and parenteral therapy has various limitations and drawbacks. Thus, a need arises to explore a possible alternate route through skin, that is, transdermal.

In conventional medicine, the antiemetic treatment comes along with certain side effects. Hence, turning to safe, effective, and time-tested system of medicine, a Unani drug formulation would be a preferable option.

\section{Objectives}

The aim of the present study was to formulate and evaluate a Unani transdermal patch that could be used for antiemetic therapy.

In the present formulation, incorporation of Unani ingredients such as Khardal (Brassica nigra), Zanjabeel (Zingiber officinale), Podina (Mentha arvensis), and Sirka (Vinegar) was envisaged. The main ingredient of the formulation is Khardal, and Sirka is used as an excipient [10]. According to Unani literature, Sirka possesses saree-ul-nufooz (penetration enhancer) property and is also a corrective for Khardal. Zanjabeel and Podina have been added to the formulation as these drugs have potent antiemetic action [11-13]. At the same time these drugs are said to enhance the transdermal permeation $[14,15]$. Therefore, these drugs will act as permeation enhancers, and at the same time they will produce suitable synergistic effect too.

\section{Materials and Methods}

All the ingredients of the formulation were procured from the open market. The foreign matter and impurities were inspected with naked eyes and removed. Samples of all the herbal drugs were identified by the experts of National Institute of Science Communication and Information Resources (NISCAIR), CSIR, New Delhi.

3.1. Extraction of Volatile Oils of Khardal, Zanjabeel, and Podina. For the design and development of an antiemetic formulation as a novel dosage form, firstly volatile oils from Khardal seeds, Zanjabeel rhizomes, and Podina leaves were extracted using Clevenger apparatus. The apparatus consisted of one round bottom flask of $1000 \mathrm{~mL}$ which was connected to the separator, in which the oil was automatically separated from the distillate in a graduated tube, thereby permitting a direct reading of the quantity of oil collected. This separator was connected to a condenser. The heat during the oil collection was kept at moderate temperature $\left(50-70^{\circ} \mathrm{C}\right)$ and was adjusted during the course of experiment [16].
3.2. Preparation of Calibration Curve for Khardal Oil. A standard curve was prepared by dilution method. A stock solution of $10 \mu \mathrm{L}$ in $10 \mathrm{~mL}$ of methanol was used for making different concentrations of $1,2,3,4$, and $5 \mu \mathrm{L} / \mathrm{mL}$, respectively. The absorbances of these solutions were determined spectrophotometrically at $\lambda \max$ of $304 \mathrm{~nm}$ [17].

3.3. Preparation and Optimization of Emulsion. An oil-inwater $(\mathrm{o} / \mathrm{w})$ emulsion was prepared using tween 80 as surfactant and ethanol as cosurfactant. The oil phase was prepared by taking $75 \%$ of Khardal oil and $25 \%$ of mixture of equal parts of Zanjabeel oil and Podina oil. The aqueous phase used was 5\% solution of Sirka. Emulsions were prepared in different ratios of oil phase:surfactant:aqueous phase $(\mathrm{O}: \mathrm{S}: \mathrm{A})$ and kept at room temperature for one month to check their stability. After optimization, the most stable emulsion was selected for dosage form development [17].

3.4. Formulation of an Antiemetic Unani Transdermal Patch. The patch was prepared by solvent evaporation technique. Initially, $4 \%$ solution of water and ethanol mixture (taken in the ratio $1: 1$ ) was prepared. Then $4 \%$ lactic acid solution was prepared using the previously prepared solution. Then $5 \mathrm{~mL}$ of this solution was taken and the temperature of this solution was maintained at $37 \pm 1^{\circ} \mathrm{C}$ using a hot plate. Later on, $125 \mathrm{mg}$ of chitosan was slowly and gradually added into it and dissolved using magnetic stirrer. After the complete dissolution of chitosan, $1 \mathrm{~mL}$ of PEG-400 (Polyethylene glycol) was added which was followed by addition of $1 \mathrm{~mL}$ of distilled water. The mixture was stirred well to obtain a thick uniform solution. Then $1 \mathrm{~mL}$ of previously optimized emulsion was added dropwise and stirred well. The solution was then poured into the mould having an area of $4 \times 2 \mathrm{~cm}^{2}$ and left overnight for drying at room temperature. After drying, two patches of size $2 \times 2 \mathrm{~cm}^{2}$ were obtained [18].

\subsection{Evaluation of Prepared Patches}

3.5.1. Organoleptic Characteristics. The prepared patch was physically inspected for its appearance, colour, clarity, flexibility, and smoothness.

3.5.2. Thickness. The thickness of patch was measured by Vernier calipers. The thickness uniformity was measured at different sites and average was calculated [19].

3.5.3. Weight Uniformity. Three patches of equal size were taken and weighed on electronic balance to check for weight variation [19].

3.5.4. Folding Endurance. The patch was taken and folded repeatedly at same point till it breaks. The number of times patch could be folded without breaking was noted [20].

3.5.5. Moisture Content. The prepared patch was weighed and kept in the dessicator containing fused calcium chloride for about 24 hours. After that it was taken out and weighed again 
[20]. The percentage of moisture content was calculated on the basis of the following formula:

$$
\begin{aligned}
& \text { Percentage of moisture content } \\
& =\frac{[\text { Initial weight }- \text { Final weight }]}{\text { Final weight }} \times 100 .
\end{aligned}
$$

3.5.6. Drug Content. The patch was dissolved in methanol and the remaining volume was made up with distilled water to $100 \mathrm{~mL}$. Then the solution was filtered and the absorbance of the solution was taken at $304 \mathrm{~nm}$ and concentration was calculated [21].

3.5.7. In Vitro Permeation Study of Patch. The in vitro permeation study of the prepared patch was carried out through egg shell membrane because the egg shell membrane resembles human stratum corneum as it consists mainly of keratin [22]. The membrane was accordingly prepared before use [23]. The water in the outer jacket of the cell was warmed and set at $37 \pm 1^{\circ} \mathrm{C}$ throughout the experiments to provide a skin surface temperature. Phosphate buffer solution of $\mathrm{pH} 7.4$ was used as dissolution medium in the receptor compartment. A $5 \times 5 \mathrm{~mm}^{2}$ piece of patch was taken and applied over the mounted membrane in diffusion cell. After that, the samples were withdrawn from the receptor compartment at regulated intervals. The sampling schedule was at $0,15,30$, and 60 minutes for the first hour of release and then it was at every hour interval till 6th hour of release. After that the whole system was kept in its normal position overnight and then next day reading was taken at 24th hour. One $\mathrm{mL}$ of the receptor solution was collected as sample each time and simultaneously one $\mathrm{mL}$ of phosphate buffer solution was added back to the receptor cell for maintaining the same initial volume of the receptor cell solution. The collected samples were analysed using UV-Vis spectrophotometer [19].

\section{Results and Discussion}

Vomiting/emesis is an emergent situation for which oral route of medication is usually not suited, and the medication is provided en route parenterally which is not available in Unani system of medicine. However, there are a number of antiemetic formulations mentioned in the celebrated writings of the Unani physicians which are topically applied over the skin to achieve desired therapeutic action. So, a pharmaceutical strategy was envisaged to generate significant scientific data by designing and developing a novel, safe, noninvasive, and patient-friendly dosage form, that is, transdermal drug delivery dosage form.

For the design and development of antiemetic formulation into novel dosage form, firstly volatile oils from different ingredients were extracted. The rationale behind extraction of volatile oils is that according to literature volatile oil form is best suited for transdermal drug delivery as it can penetrate more through the skin and the dosage is also reduced. Also in this case volatile oil contained the active constituents of the respective drugs.

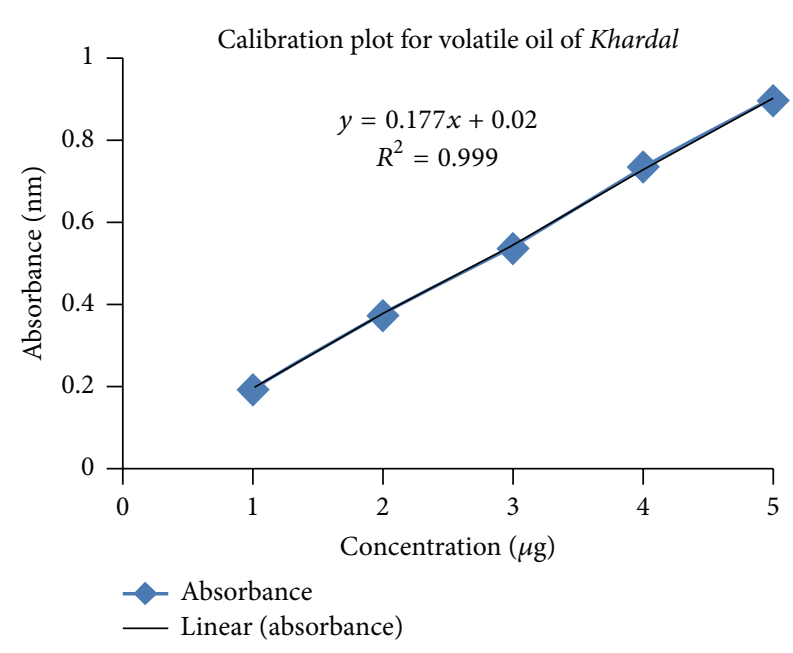

FIGURE 1: Calibration curve of volatile oil of Khardal.

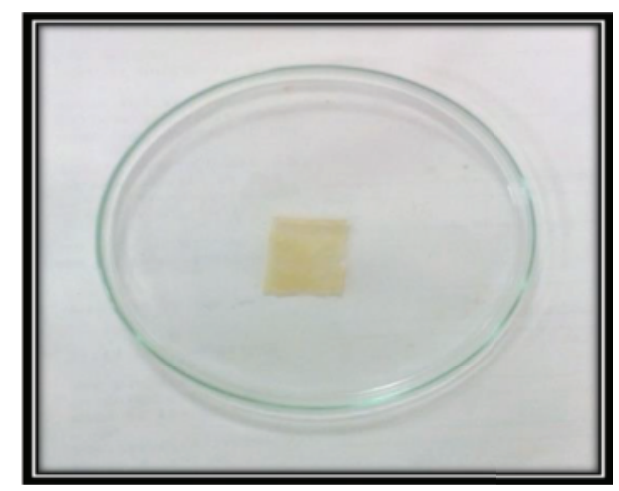

FIGURE 2: Sample of prepared Unani transdermal antiemetic patch.

TABLE 1: Standard calibration data for volatile oil of Khardal.

\begin{tabular}{lcc}
\hline Serial number & Concentration $(\mu \mathrm{g})$ & Absorbance $(\mathrm{nm})$ \\
\hline$(1)$ & 15.625 & 0.077 \\
$(2)$ & 31.25 & 0.112 \\
$(3)$ & 62.5 & 0.171 \\
$(4)$ & 125 & 0.285 \\
$(5)$ & 250 & 0.501 \\
$(6)$ & 500 & 0.932 \\
\hline
\end{tabular}

Initially a standard calibration curve for Khardal oil was prepared. The absorbance values are given in Table 1. Using concentration and absorbance data, Beer and Lambert's plot was obtained. The plot is shown in Figure 1.

4.1. Organoleptic Characteristics. The prepared patches were slightly opaque, pale coloured, jellified preparations showing good flexibility and smoothness as given in Table 2. A sample of prepared patch is shown in Figure 2.

4.2. Thickness. The mean thickness of prepared patches was $0.6 \pm 0.026 \mathrm{~mm}$ as given in Table 3 . 
TABLE 2: Organoleptic characteristics of the prepared patches.

\begin{tabular}{lcc}
\hline Serial number & Physical characteristic & Result \\
\hline$(1)$ & Appearance & Jellified preparation \\
$(2)$ & Colour & Pale \\
$(3)$ & Clarity & Slightly opaque \\
$(4)$ & Flexibility & Good \\
$(5)$ & Smoothness & Good \\
\hline
\end{tabular}

TABLE 3: Thickness of patch.

\begin{tabular}{lc}
\hline Serial number & Thickness $(\mathrm{mm})$ \\
\hline$(1)$ & 0.63 \\
$(2)$ & 0.58 \\
$(3)$ & 0.59 \\
\hline Mean \pm SD & $0.6 \pm 0.026$ \\
\hline
\end{tabular}

TABLE 4: Weight uniformity of patch.

\begin{tabular}{lc}
\hline Serial number & Weight $(\mathrm{gm})$ \\
\hline$(1)$ & 0.257 \\
$(2)$ & 0.249 \\
$(3)$ & 0.248 \\
\hline Mean \pm SD & $0.251 \pm 0.005$ \\
\hline
\end{tabular}

TABLE 5: Folding endurance of patch.

\begin{tabular}{lc}
\hline Serial number & Folding endurance \\
\hline$(1)$ & 75 \\
$(2)$ & 78 \\
$(3)$ & 79 \\
\hline Mean \pm SD & $77.33 \pm 2.081$ \\
\hline
\end{tabular}

TABLE 6: Moisture content of patch.

\begin{tabular}{lc}
\hline Serial number & Moisture content (\%) \\
\hline$(1)$ & 5.07 \\
$(2)$ & 4.71 \\
$(3)$ & 4.96 \\
\hline Mean \pm SD & $4.91 \pm 0.184$ \\
\hline
\end{tabular}

4.3. Weight Uniformity. The mean weight of prepared patches was $0.251 \pm 0.005 \mathrm{gm}$ as given in Table 4 .

4.4. Folding Endurance. The mean folding endurance of prepared patches was $77.33 \pm 2.081$ as given in Table 5 .

4.5. Moisture Content. The mean moisture content of prepared patches was $4.91 \pm 0.184 \%$ as given in Table 6 .

4.6. Drug Content. The mean drug content of the prepared patches was $0.284 \pm 0.007 \mathrm{mg}$ in $\mathrm{w} / \mathrm{w}$ ratio with the weight of patch as given in Table 7 .

4.7. In Vitro Permeation Study of Patch. The in vitro permeation studies of the prepared transdermal patches indicated

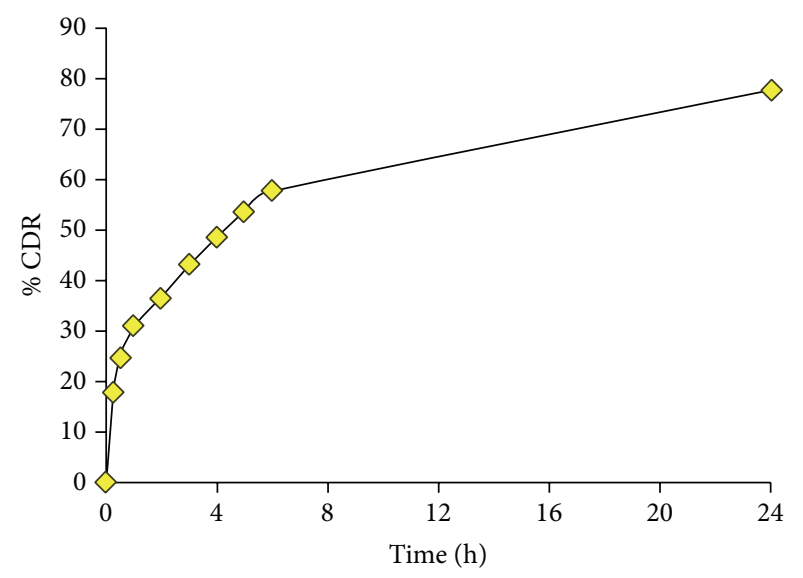

FIGURE 3: In vitro permeation study of patch.

TABLE 7: Drug content of patch.

\begin{tabular}{lc}
\hline Serial number & Drug content $(\mathrm{mg})$ \\
\hline$(1)$ & 0.292 \\
$(2)$ & 0.281 \\
$(3)$ & 0.278 \\
\hline Mean \pm SD & $0.284 \pm 0.007$ \\
\hline
\end{tabular}

TABLE 8: In vitro permeation study of patch.

\begin{tabular}{lccc}
\hline Serial number & $\begin{array}{c}\text { Time of } \\
\text { collection }\end{array}$ & $\begin{array}{c}\text { Concentration } \\
(\mu \mathrm{L} / \mathrm{mL})\end{array}$ & \% CDR \\
\hline$(1)$ & 0 minutes & 0 & 0 \\
$(2)$ & 15 minutes & 6.686 & 17.83 \\
$(3)$ & 30 minutes & 9.210 & 24.56 \\
$(4)$ & 1 hour & 11.584 & 30.89 \\
$(5)$ & 2 hours & 13.699 & 36.53 \\
$(6)$ & 3 hours & 16.136 & 43.03 \\
$(7)$ & 4 hours & 18.233 & 48.62 \\
$(8)$ & 5 hours & 20.051 & 53.47 \\
$(9)$ & 6 hours & 21.716 & 57.91 \\
$(10)$ & 24 hours & 29.018 & 77.38 \\
\hline
\end{tabular}

a time dependent increase throughout the study as shown in Figure 3. The drug release from patches was rapid during first hour and it slowed down thereafter. The percentage of drug release was $17.83 \%$ in 15 minutes which further increased to $24.56 \%$ in 30 minutes and reached $30.89 \%$ in one hour. The cumulative drug release increased gradually and reached $57.91 \%$ in 6 hours. Finally, at the end of study, the cumulative drug release reached a remarkable peak, that is, $77.38 \%$ in 24 hours, as given in Table 8.

\section{Conclusion}

Keeping in view the current Unani pharmaceutical scenario, it is the felt-need of the hour to envisage a research study on design and development of Unani dosage forms, since there is no parenteral dosage form available in Unani system of 
medicine. Accordingly, the study was based on design and development of an antiemetic transdermal Unani formulation in a novel dosage form for a common clinical condition, namely, vomiting/emesis (qai). The patch was found to be stable and showed no signs of skin irritation. The study shows a new approach to work in Unani pharmaceutics.

Further, a clinical study is warranted to evaluate therapeutic efficacy of this novel dosage form.

\section{Competing Interests}

There are no competing interests to declare.

\section{Acknowledgments}

The authors gratefully acknowledge the faculty of Post Graduate Department of Ilm-us-Saidla (Pharmaceutical Science), Ayurvedic \& Unani Tibbia College \& Hospital, Karol Bagh, New Delhi, for their valuable cooperation and support.

\section{References}

[1] A. I. Shembale, D. K. Borole, and R. T. Lohiya, "Useful Permeation enhancers for transdermal drug delivery: a review," International Journal of Pharmaceutical Research and Development, vol. 2, no. 5, pp. 1-6, 2010.

[2] S. R. Rathva, N. N. Patel, V. Shah, and U. M. Upadhyay, "Herbal transdermal patches: a review," International Journal of Drug Discovery and Herbal Research, vol. 2, no. 2, pp. 397-402, 2012.

[3] S. Rani, K. Saroha, N. Syan, and P. Mathur, "Transdermal patches a successful tool in transdermal drug delivery system: an overview," Der Pharmacia Sinica, vol. 2, no. 5, pp. 17-29, 2011.

[4] P. Patel, "Herbal excipients: an emerging field as a penetration enhancer in transdermal drug delivery system," International Journal of Pharmaceutical Research and Development, vol. 4, no. 2, pp. 58-68, 2012.

[5] S. D. Faldu, Design and evaluation of controlled release transdermal dosage form of cardiovascular drugs [Ph.D. thesis], Saurashtra University, Rajkot, India, 2010.

[6] B. C. Finnin and T. M. Morgan, "Transdermal penetration enhancers: applications, limitations, and potential," Journal of Pharmaceutical Sciences, vol. 88, no. 10, pp. 955-958, 1999.

[7] S. Ewing, "Black mustard (Brassica nigra)," Ethnobotanical Leaflets, In press.

[8] L. D. Kronenberg, The Ultimate Text in Constitutional Hydrotherapy, 2012.

[9] T. J. Ritter, Mother's Remedies: Over One Thousand Tried and Tested Remedies from Mothers of the United States and Canada, Old Time Remedies, 2008.

[10] M. Kabiruddin, Bayaz-e-Kabir, vol. 2, Hikmat Book Depot. ynm, Hyderabad, India.

[11] M. A. Khan, Muheet-e-Azam, vol. 3, part 2, Matba Nizami, Kanpur, India, 1892 (Persian).

[12] S. Tate, "Peppermint oil: a treatment for postoperative nausea," Journal of Advanced Nursing, vol. 26, no. 3, pp. 543-549, 1997.

[13] S. L. Vishwakarma, S. C. Pal, V. S. Kasture, and S. B. Kasture, "Anxiolytic and antiemetic activity of Zingiber officinale," Phytotherapy Research, vol. 16, no. 7, pp. 621-626, 2002.

[14] V. Singla, S. Saini, G. Singh, A. C. Rana, and B. Joshi, "Penetration enhancers: a novel strategy for enhancing transdermal drug delivery," International Research Journal of Pharmacy, vol. 2, no. 12, pp. 32-36, 2011.

[15] J. Wungsintaweekul, S. Chartwaingam, and S. Songkro, Investigation of Essential Oils from Zingiber Officinale, Zingiber Cassumunar and Curcuma Zedoaria as Skin Penetration Enhancers, PSU Knowledge Bank, 2004.

[16] K. S. Kumar, Extraction of essential oil using steam distillation [Bachelor of Technology Thesis], NIT, Rourkela, India, 2010.

[17] M. N. Saleem, Pharmaceutical Development of an Antiemetic Transdermal Unani Formulation with SOP [M.D. Unani Thesis], University of Delhi, New Delhi, India, 2015.

[18] A. S. Can, M. S. Erdal, S. Güngör, and Y. Özsoy, "Optimization and characterization of chitosan films for transdermal delivery of ondansetron," Molecules, vol. 18, no. 5, pp. 5455-5471, 2013.

[19] P. K. Suryadevara, Formulation and evaluation of antiemetic patch comprising ondansetron hydrochloride [M.S. thesis], KLE University, Belgaum, India, 2010.

[20] R. K. Reddy, S. Muttalik, and S. Reddy, "Once daily sustained release matrix tablets of nicorandil: formulation and in-vitro evaluation," AAPS Pharm Sci Tech, vol. 4, no. 4, pp. 480-488, 2003.

[21] S. Lewis, S. Pandey, and N. Udupa, "Design and evaluation of matrix type and membrane controlled transdermal delivery systems of nicotine suitable for use in smoking cessation," Indian Journal of Pharmaceutical Sciences, vol. 68, no. 2, pp. 179184, 2006.

[22] J. M. Haigh and E. W. Smith, "The selection and use of natural and synthetic membranes for in vitro diffusion experiments," European Journal of Pharmaceutical Sciences, vol. 2, no. 5-6, pp. 311-330, 1994.

[23] V. Shah, S. Raval, S. Peer, and U. M. Upadhyay, "A comparative evaluation of different membranes for their diffusion efficiency: an in-vitro study," Pharma Science Monitor, vol. 1, no. 2, pp. 4149, 2010. 

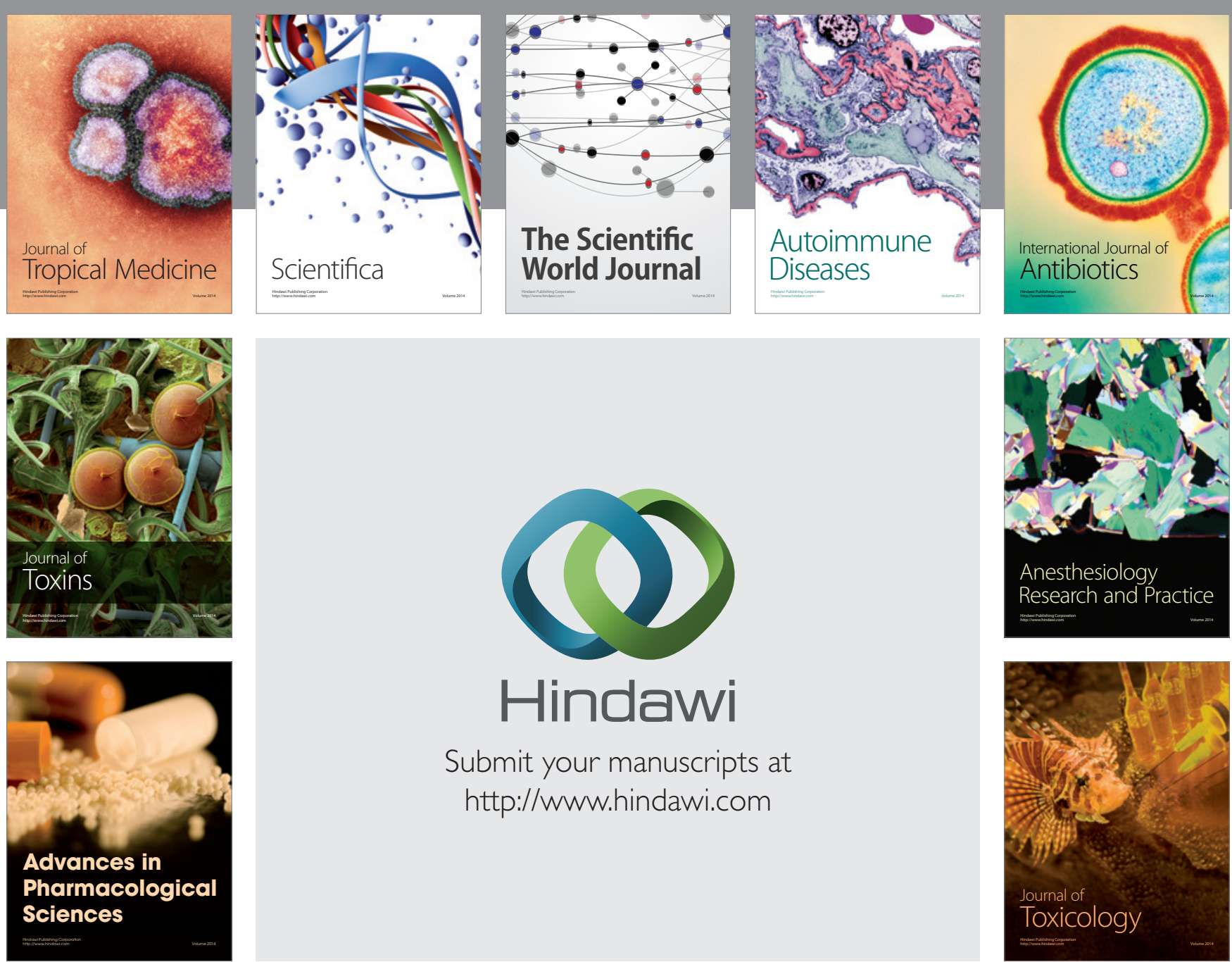

\section{Hindawi}

Submit your manuscripts at

http://www.hindawi.com
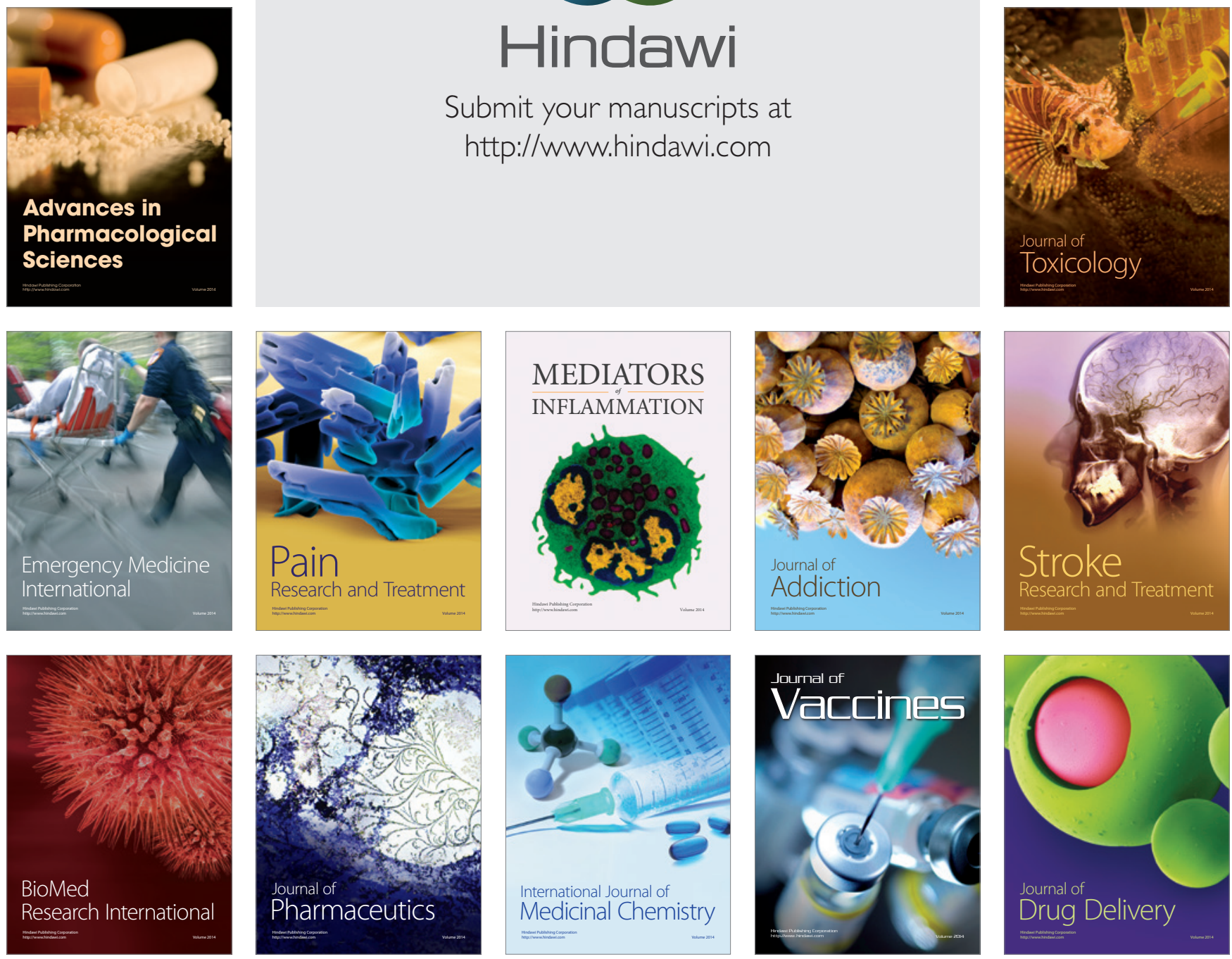